\title{
Pharmacovigilance by World Health Organisation Uppsala Monitoring Center Causality Assessment Algorithm in Medicine Ward of Tertiary Care Hospital of New Delhi
}

\author{
Shah $R C,{ }^{1^{*}}$ Karki $S,{ }^{1}$ Parajuli SB, ${ }^{2}$ Bhattrai $P,{ }^{3}$ Chowdhary $P K^{4}$
}

\begin{abstract}
Affiliation:
1. Lecturer, Department of Pharmacology, Birat Medical College \& Teaching Hospital, Tankisinuwari, Morang, Nepal.

2. Lecturer, Department of Community Medicine, Birat Medical College \& Teaching Hospital, Tankisinuwari, Morang, Nepal.

3. Lecturer, Department of Physiology, Birat Medical College \& Teaching Hospital, Tankisinuwari, Morang, Nepal.

4. Professor, Department of Pharmacology, Birat Medical College \& Teaching Hospital, Tankisinuwari, Morang, Nepal.
\end{abstract}

\section{ARTICLE INFO \\ Article History \\ Received : 15 Aug, 2016 \\ Accepted : $15 \mathrm{Sep}, 2016$ \\ Published : 20 Dec, 2016}

(C) Authors retain copyright and grant the journal right of first publication with the work simultaneously licensed under Creative Commons Attribution License CC - BY 4.0 that allows others to share the work with an acknowledgement of the work's authorship and initial publication in this journal.

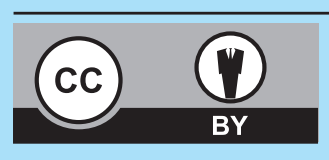

$$
\begin{gathered}
\text { * Corresponding Author } \\
\text { Mr. Ram Chandra Shah } \\
\text { Lecturer } \\
\text { Department of Pharmacology, } \\
\text { Birat Medical College \& Teaching Hospital } \\
\text { Tankisinuwari-02, Morang, Nepal } \\
\text { Email: rampharmashah@gmail.com }
\end{gathered}
$$

\section{Citation}

Shah RC, Karki S, Parajuli SB, Bhattarai P, Chowdhary PK. Pharmacovigilance by World Health Organisation Uppsala Monitoring Center Causality Assessment Algorithm in Medicine Ward of Tertiary Care Hospital of New Delhi. BJHS2016;1(1) 1:61-64.

\section{ABSTRACT}

\section{Introduction}

Pharmacovigilance is not new to India and has in fact been going on since 1998. Adverse drugs reaction (ADRs) are important causes of morbidity and mortality all over the world. They account for approximately $10-20 \%$ of all hospitalized patients. The overall incidence of serious ADRs is $6.7 \%$ and that of fatal is $0.32 \%$.

\section{Objective}

The objectives of the study was to find the pattern of adverse drug reactions in patients attending medicine ward of a tertiary care center of New Delhi.

\section{Methodology}

A prospective study was conducted from March 2013 to December 2013. On the basis of WHO-UMC causality assessment algorithm, the incidence and pattern of ADRs were assessed from 300 patients of 18 to 70 years of age. The collected data was entered in Microsoft Excel, Common Terminology Criteria for Adverse Events (CTCAE) and analysed by SPSS.

\section{Results}

The incidence of ADRs was found to be $13.67 \%$. More than one ADRs has been reported from some patients. The gender of the patients has no significance in the occurance of ADRs $(p=0.194)$. Highest number of ADRs were found in gastrointestional system followed by central nervous system. Gastrointestional ADRs were must commonly associated with the uses of antimicrobials. The most frequently seen ADRs were diarrhea, gastritis, abdominal pain followed by nausea and vomiting. Decreased level of consciousness (sedation, drowsiness) followed by dizziness and tremors were the frequent $A D R s$ related to the central nervous systems. Based on WHO-UMC causality assessment algorithm, it was observed that a total of 57 ADRs were possible and 2 were probable. No other causality assessment category was observed.

\section{Conclusion}

The ADRs incidence was common even in a tertiary care center. The Gastrointestional and central nervous system disorder were common. The concern of Pharmacovigilance should be initiated.

\section{KEY WORDS}

Adverse drug reactions, antimicrobials, pharmacovigilance, WHO-UMC 


\section{INTRODUCTION}

Pharmacovigilance is the science and activities relating to the detection, assessment, understanding and prevention of adverse effects or any other drug related problems. ${ }^{1}$ Recently its concerns have been grown to include herbals, traditional and complementary medicines, blood products, biological or medical devices and vaccines. Pharmacovigilance is not new to India and has in fact been going on since $1998^{2}$ when India decided to join the Uppsala Centre for adverse event monitoring. ADRs are important causes of morbidity and mortality all over the world. They account for approximately $10-20 \%$ of all hospitalized patients. ${ }^{3,4}$ The overall incidence of serious ADRs is $6.7 \%$ and that of fatal is $0.32 \% .^{5}$ It has been estimated that every year around $1,06,000$ people die in USA because of ADRs which makes these reactions fourth leading cause of death after heart diseases, cancer and stroke. ${ }^{6}$ The estimated cost of mortality and morbidity related to ADRs in USA is more than \$75 billion annually. ${ }^{7}$ In 1893 , the Lancet formed a commission that invited doctors in Britain and its colonies to report anesthesia related deaths. This was done after a 15 year Hannah Greener died after administration of chloroform, a new anesthetic at that time. ${ }^{8}$ This reporting system thus formed the fore-runner of today's spontaneous reporting system. ${ }^{9}$ The study was conducted to analyse the pattern of observed Adverse Drug Reactions using World Health Organisation-Uppsala Monitoring Center (WHO-UMC) Causality Assessment Algorithm in medicine ward of All India Institute of Medical Sciences (AIIMS).

\section{METHODOLOGY}

A Prospective study was carried out from $1^{\text {st }}$ March 2013 to $30^{\text {th }}$ December 2013. The total number of patients were 300 . Before enrolling the patients, they were provided with patient's information sheet and the informed consent was taken. All the 300 admitted patients were observed daily whether they developed any of adverse events (AE) or not. If any $A E$ was identified, it was written down in Central Drugs Standard Control Organization (CDSCO) ADR reporting format. The association was observed between the drug and adverse events using WHO-UMC causality assessment scale. Data obtained were entered in Microsoft Excel and analysed by SPSS. The research was approved from AIIMS Institutional Ethics Committee.

\section{RESULTS}

Among the 300 patients enrolled in the study 41 patients (13.66\%) developed 59 ADRs. Among the 59 ADRs, 31 were observed in males (52.54\%) and 28 in females (47.46\%). The mean age of study participants among the male was 42.36 year and female was 40.42 years. The gender distribution of the study participants shown in figure 1.

\section{Figure 1: Gender distribution of participants}

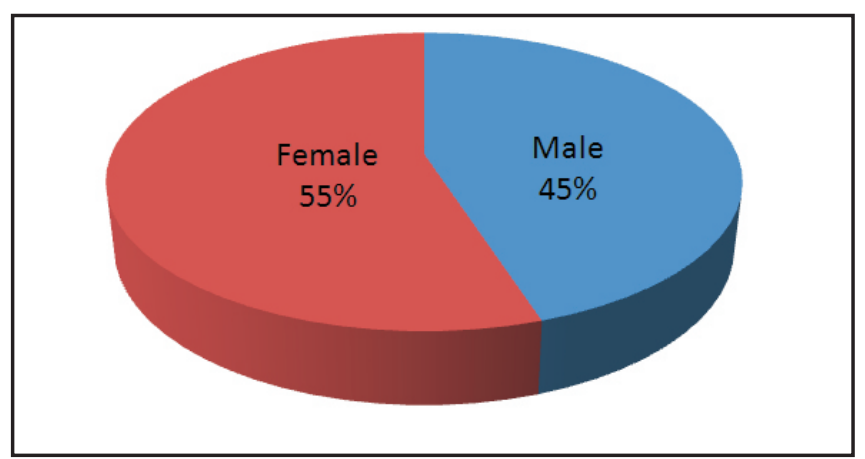

The mean age of these 41 patients who developed ADRs was 41.46 years. It was observed that patients of younger age group (28-37 years) experienced maximum number of ADRs (28.81\%) and least was observed in older age group (48-57 years) who had experienced $8.47 \%$ of the total ADRs.

\section{Figure 2: Distribution of ADRs based on age category.}

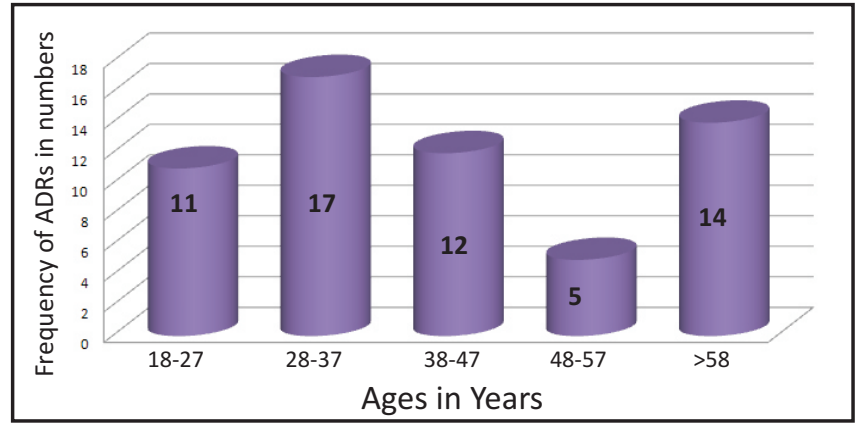

There was no significant difference of ADRs in males and females $(p=0.194)$ as shown in (Table 1$)$.

\section{Table-1: Distribution of ADRs on the basis of gender}

\begin{tabular}{|l|c|c|c|}
\hline \multirow{2}{*}{ Gender } & \multicolumn{2}{|c|}{ ADRs } & \\
\cline { 2 - 4 } & Yes (\%) & NO (\%) & P Value \\
\hline Male & $104(77.04)$ & $31(22.96)$ & 0.194 \\
\hline Female & $137(83.03)$ & $28(16.97)$ & \\
\hline
\end{tabular}

Among the observed 59 ADRs in 41 patients, majority developed only one ADR. The major ADR was diarrhea followed by gastritis and depressed level of consciousness (sedation). The detailed has been given in Table 2. Among the patients observed with ADRs, the most common primary diseases for admission were tuberculosis and infections (Table3). Antimicrobials (42.37\%) were found to be most commonly used drugs that caused ADRs followed by drugs used to treat central nervous system disorders, immunosuppressant drugs and respiratory drugs respectively (Table 4). 


\section{Table 2: Different ADRs $(n=59)$}

\begin{tabular}{|lll|}
\hline ADRs & Number & Percent \\
\hline Abdominal Pain & 3 & 5.08 \\
\hline Cough & 3 & 5.08 \\
\hline Sedation & 6 & 10.17 \\
\hline Diarrhea & 11 & 18.64 \\
\hline Dizzeness & 1 & 1.69 \\
\hline Dry Mouth & 2 & 3.39 \\
\hline Dysgeusia & 1 & 1.69 \\
\hline Fever & 2 & 3.39 \\
\hline Gastritis & 7 & 11.86 \\
\hline Oral Ulcer & 2 & 3.39 \\
\hline Hyperurecemia & 1 & 1.69 \\
\hline Nausea & 1 & 1.69 \\
\hline Pain & 2 & 3.39 \\
\hline Palpitation & 3 & 5.08 \\
\hline Pruritus & 3 & 5.08 \\
\hline Tremors & 1 & 1.69 \\
\hline Urtricaria & 2 & 3.39 \\
\hline Vomiting & 3 & 5.08 \\
\hline
\end{tabular}

Table 3 : Distribution of ADRs based on primary disease at $\operatorname{admission}(n=59)$

\begin{tabular}{|lll|}
\hline Dignosis & Number & Percent \\
\hline Blood Related Disorder & 1 & 1.69 \\
\hline Coronary Artery Disease & 3 & 5.08 \\
\hline Central Nervous System Disease & 3 & 5.08 \\
\hline Cardiovascular Disease & 6 & 10.17 \\
\hline Diabetes Mellitus & 2 & 3.39 \\
\hline Endocrinological Disease & 2 & 3.39 \\
\hline Fever & 1 & 1.69 \\
\hline Gastrointestinal Disease & 1 & 1.69 \\
\hline HIV & 2 & 3.39 \\
\hline Infections & 10 & 16.95 \\
\hline Immunological Disease & 6 & 10.17 \\
\hline Kidney Related Disease & 3 & 5.08 \\
\hline Tuberculosis & 9 & 15.25 \\
\hline Other Respiratory Diseases & 10 & 16.95 \\
\hline
\end{tabular}

Table 4: Distribution of drugs involved in ADRs $(n=59)$

\begin{tabular}{lll}
\hline Drugs & Number & Percent \\
\hline Antimicrobials & 25 & 42.37 \\
\hline Antihypertensives & 3 & 5.08 \\
\hline Central Nervous System Drugs & 5 & 8.47 \\
\hline Anti-Coagulants & 1 & 1.69 \\
\hline Diuretics & 2 & 3.39 \\
\hline Immunosuppressive Drugs & 5 & 8.47 \\
\hline Anti-arthritic Drugs & 1 & 1.69 \\
\hline Anti-platelets & 3 & 5.08 \\
\hline Respiratory Drugs & 5 & 8.47 \\
\hline Anti-tuberculosis & 4 & 6.78 \\
\hline Others & 5 & 8.47 \\
\hline Total & 59 & 100.00 \\
\hline
\end{tabular}

It was observed that out of 59 ADRs, 57 were possible and 2 were probable. This suggests that most of the ADRs categorized as 'possible' had negative re-challenge, the patient recovered within a plausible length of time following withdrawal of the drug. No other causality assessment category was observed (Table 5).

\section{Table 5: Patterns of ADRs on the basis of WHO-UMC algorithm} $(n=59)$

\begin{tabular}{|ccc|}
\hline Causality Assessment & Number & Percentaget \\
\hline Probable & 2 & 3.39 \\
\hline Possible & 57 & 96.61 \\
\hline Total & 59 & 100.00 \\
\hline
\end{tabular}

\section{DISCUSSION}

One of the major cause of morbidity and mortality all over the world is adverse drug reaction. The incidence of ADRs in hospital varies from $10-20 \% .{ }^{10}$ According to FDA drug review, overall $51 \%$ of approved drugs have serious adverse effects that could not be detected prior to their approval. ${ }^{11}$ In a study by Sjoquist $F^{12} 30-50 \%$ of these ADRs could have been prevented since they were dose dependent. However, studies conducted are few and the reported incidence of ADRs varies greatly. Arulmani $R$ et $a,{ }^{13}$ reported the incidence of ADRs as $9.8 \%$, where as Gor AP et al, ${ }^{14}$ reported it as $3 \%$. However incidence of ADRs was higher (16.6\%) as reported by Padmaja $U$ et $a l .{ }^{15}$ This may be due to differences in certain measures such as study design, data collections, definition of ADRs, the diversity of drugs used and the heterogenecity of 
the investigated populations. A study by Pir Mohammed et $\mathrm{al}^{16}$ had reported that the incidence of ADR frequencies residing between $10-20 \%$ among the patients in the hospital. The occurrence of ADRs in the present study was $13.66 \%$ which agreed with the review by Pir Mohammed et al. ${ }^{16}$ Various factors are responsible in such variability of ADRs. These include genetic, ethnic, dietary, environmental and rational drug use. Majority of ADRs observed in our study were in the gastrointestinal disorders in system organ classification (SOC). This was consistent with previous study by Natalie et al, where gastrointestinal ADRs were most frequent and were commonly associated with the antimicrobials. ${ }^{17}$ To strengthen and further emphasize the validity of our findings, we carried out causality assessment using WHO-UMC's scale where most of the ADRs were possible and few were probable.

\section{CONCLUSION}

Incidence of adverse drug reactions in the present study was within the reported range mentioned in the literature. All the ADRs were nontoxic reactions and the gastrointestinal disorder was the most common ADR. The safety assessment should be considered as an integral part of everyday clinical practice. There are new drugs being launched in the market and to ensure safe use of drugs, there is a need of pharmacovigilance.

\section{REFERENCES}

1. WHO. International drug monitoring. The importance of pharmacovigilance. Safety monitoring of medical products. Geneva: WHO 2002.

2. Deepa, A. 'Pharmacovigilance obligations of the pharmaceutical companies in India', India J pharmacol, vol.40, Feb, 2008.

3. Muehlberger N, Schneeweiss S, Hasford J. Adverse Drug Reaction Monitoring-cost and benefit consideration. Part I: frequency of adverse drug reactions causing hospital admissions. Pharmacoepidem and drug safety $1997 ; 6($ S3): $71-77$

4. Classen DC Pestotnik SL, Evans RS Lloyd JF burke JP. Adverse drug events in hospitalized patients-excess length of stay extra costs and attributable mortality. JAMA 1997; 277:301-6.

5. Lazarou J, Pomeranz BH, Corey PN. Incidence of adverse drug reactions in hospitalized patients: A meta-analysis of prospective studies JAMA1998; 279: 1200-1205.

6. Leventhal JM, Hutchinson TA, Kramer MS, et al. An algorithm for the operational assessment of adverse drug reactions:III. Results of tests among clinicians. JAMA 1979; 242: 1991- 4.

7. Johnson JA, Bootsman JL. Drug related morbidity and mortality: a cost of illness model. Arch Intern Med. 1995; 155: 1949-56.

8. Commission on Anesthetics. Lancet 1893; 1: 629-38.

9. Rawlins MD. Pharmacovigilance: paradise lost regained or postponded ? J R Coll Physicians Lond 1995: 29: 41-49.

\section{RECOMMENDATIONS}

Information from this study may improve the understanding of pharmacovigilance and better use of therapeutic drugs. This will directly benefit the patient as well as health care provider and indirectly to other stakeholders. As the study was conducted in AIIMS, one of the tertiary care hospital, the data may benefit in other health care services too.

\section{LIMITATIONS OF THE STUDY}

The results may not be generalized because the study involved only one of the major departments and was conducted in a tertiary care center that accepted patients with the complex of diseases. We may have missed some of the patients with delayed onset of ADRs. Some respondents with many prescribed drugs and co-morbid conditions reported several complaints, it was difficult to attribute symptoms to specific drugs.

\section{ACKNOWLEDGEMENTS}

We are grateful to all the participants in this study. We are also thankful to All India Institute of Medical Sciences (AIIMS); New Delhi for creating platform to do this research. Our especial thanks goes to Prof. Dr. Kamal Kishore; Department of Pharmacology; Prof. Dr. Naveet Wig; Department of Medicine; AlIMS; New Delhi.

\section{CONFLICT OF INTEREST}

No conflict of interest declared.

10. Biswas $P$, Biswas AK. Setting standards for proactive pharmacovigilance in India. The way forward. Indian Journal of Pharmacology 2007; 39(3):124-128.

11. Karch FE, Lasagna L. Adverse drug reactions: A critical review. JAMA 1975; 234: 1236-41.

12. Sjoqvist F. Drug safety in relation to efficacy: The view of a clinical pharmacologist. PharmacolToxicol 2000; 86 (suppl 1):30-32.

13. Arulmani R, Rajendran SD. Adverse drug reactions monitoring in a secondary care hospital in south India. Br J ClinPharmacol 2007; 65(2):210-216.

14. Gor AP, Desai SV. Adverse Drug Reactions (ADR) in the inpatients of medicine department of a rural tertiary care teaching hospital and influence of pharmacovigilance in reporting ADR 2008;40:37-40.

15. Padmaja U, Adhikari P, Pereira P. A prospective analysis of adverse drug reactions in a South Indian Hospital. Online J Health Allied Scs. 2009;8 (3):12.

16. Permohamed $\mathrm{M}$ et al, Adverse drug reaction. British Medical Journal 2000; 318:1295-1298.

17. Natalie et al, Chronic peptic ulceration and non-steroidal antiinflammatory drugs: more to be said about NSAIDS? Gastroenterology 1992; 102: 1074-1078. 